The final, definitive version of this article has been published in the Journal Review of Educational Research, 68, 1998, p. 179-202, (C) SAGE Publications Ltd. 1998, by SAGE Publications Ltd. at the Review of Educational Research page: http://rer.sagepub.com on SAGE

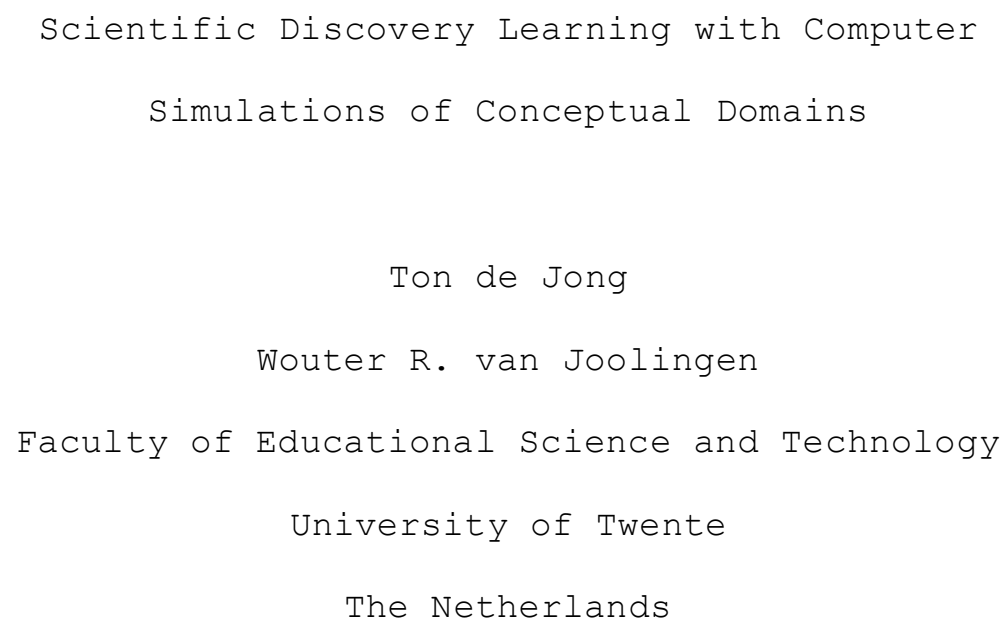


Scientific Discovery Learning with Computer Simulations

Abstract

Scientific discovery learning is a highly self-directed and constructivistic form of learning. A computer simulation is a type of computer-based environment that is very suited for discovery learning, the main task of the learner being to infer, through experimentation, characteristics of the model underlying the simulation. In this article we give a review of the observed effectiveness and efficiency of discovery learning in simulation environments together with problems that learners may encounter in discovery learning, and we discuss how simulations may be combined with instructional support in order to overcome these problems. 
Scientific Discovery Learning with Computer Simulations

\section{Scientific Discovery Learning with Computer \\ Simulations of Conceptual Domains}

In the field of learning and instruction we now see an impressive influence of the so-called "constructivistic" approach. In this approach a strong emphasis is placed on the learner as an active agent in the knowledge acquisition process. As in the objectivistic tradition, where developments were followed and encouraged by the computer based learning environments, such as programmed instruction, tutorials, and drill and practice programs (Alessi \& Trollip, 1985), also within the constructivistic approach we find computer learning environments that help to advance developments. Examples are hypertext environments (see e.g., Gall \& Hannafin, 1994), concept mapping environments (see e.g., Novak \& Wandersee, 1990), simulations (De Jong, 1991; Reigeluth \& Schwartz, 1989), and modeling environments (e.g., disessa \& Abelson, 1986; Riley, 1990; Smith, 1986).

In this article we concentrate on the use of computer simulations for learning because learning with simulations is closely related to a specific form of constructivistic learning, namely scientific discovery learning. First of all, we give a short introduction to the two key terms in this article (computer simulation and scientific discovery learning) followed by a short overview of studies that compared unsupported simulation based discovery learning to some form of expository teaching. These studies show that advantages of 
simulation based learning are not always met, and suggest that one of the reasons for this is that learners have problems with discovery learning. This conclusion brings us to the main questions in this article: "what are problems that learners have in discovery learning?", and "how can we design simulation environments that support learners in overcoming these problems?"

Computer simulations are programs that contain a model of a system (natural or artificial, e.g., equipment), or a process. Computer simulations can broadly be divided into two types: simulations containing a conceptual model, and those based on an operational model. Conceptual models hold principles, concepts, and facts related to the (class of) system(s) being simulated. Operational models include sequences of cognitive and non-cognitive operations (procedures) that can be applied to the (class of) simulated system(s). Examples of conceptual models can be found in economics (Shute \& Glaser, 1990), and in physics (e.g., electrical circuits, White \& Frederiksen, 1989 ; 1990). Operational models can, for example, be found in radar control tasks (Munro, Fehling, \& Towne, 1985). Operational models are generally used for experiential learning, in a discovery learning context we mainly find conceptual simulations. Conceptual models still cover a wide range of model types such as qualitative vs. quantitative models, continuous vs. discrete, and static vs. dynamic models (see Van Joolingen \& De Jong, 1991a). Models may also differ 
considerably in complexity, and range from very simple straightforward models, e.g., simple Mendelian genetics (Brant, Hooper, \& Sugrue, 1991) to very complex models, e.g., the medical simulation HUMAN (Coleman \& Randall, 1986) in which 200 variables and parameters can be changed. Also, specific characteristics like the place of variables in the model, or the distance between theoretical and operational variables characterize the conceptual model (Glaser, Schauble, Raghavan, \& Zeitz, 1992). In scientific discovery learning the main task of the learner is to infer the characteristics of the model underlying the simulation. The learners' basic actions are changing values of input variables and observing the resulting changes in values of output variables (De Jong, 1991; Reigeluth \& Schwartz, 1989). Originally, the means of giving input and receiving output of simulation environments were rather limited, but now increasingly sophisticated interfaces using direct manipulation for input, and graphics and animations as outputs, are emerging (e.g., Härtel, 1994; Teodoro, 1992; Kozma, Russel, Jones, Marx, \& Davis, 1996) with as the latest development virtual reality environments (see e.g., Thurman \& Mattoon, 1994).

Discovery learning finds its roots in the Gestalt psychology and the work by Bruner (1961). The field of study into discovery learning has, over the last few decades, moved away from concept discovery (as in Bruner's studies) towards what has been called "scientific discovery learning" (Klahr \& 
Dunbar, 1988; Reimann, 1991). Theories on scientific discovery learning are usually based on theories of scientific discovery. Rivers and Vockell (1987), for example, describe a plan (design experiment), execute (carry out experiment and collect data), and evaluate (analyze data and develop hypothesis) cycle. Friedler, Nachmias, and Linn (1990) say that scientific reasoning comprises the abilities to "(a) define a scientific problem; (b) state a hypothesis; (c) design an experiment; (d) observe, collect, analyze, and interpret data; (e) apply the results; and (f) make predictions on the basis of the results." (p. 173). De Jong and Njoo (1992) added the distinction between transformative processes (processes that directly yield knowledge such as the ones mentioned by Friedler et al., and Rivers \& Vockell) and regulative processes (processes that are necessary to manage the discovery process such as such as $\underline{\text { planning }}$ and $\underline{\text { monitoring) }} \doteq$ A second group of theories on scientific discovery learning finds its inspiration in the work by Simon (cf. Kulkarni \& Simon, 1988; Qin \& Simon, 1990; Simon \& Lea, 1974). A major contribution in this field is Klahr and Dunbar's (1988) SDDS theory (Scientific Discovery as Dual Search) that takes two spaces as central concepts: hypothesis

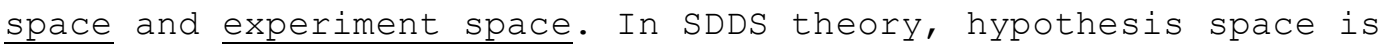
a search space consisting of all rules possibly describing the phenomena that can be observed within a domain. Experiment space consists of experiments that can be performed with the domain and the outcomes of these experiments. Albeit the first 
emphasis in SDDS theory is on the structure of the search spaces, Klahr and Dunbar have paid considerable attention to discovery processes.

In an early overview on computer-based education, BangertDrowns, Kulik, and Kulik (1985) report that simulation based learning does not raise examination scores. Later studies that contrasted (sometimes as part of a larger set of comparisons) learning from "pure" simulation (containing conceptual models) with learning from some form of expository instruction (computer tutorial, classroom) cover a variety of domains, such as biology (Rivers \& Vockell, 1987), economics (Grimes \& Willey, 1990), Newtonian mechanics (Rieber, Boyce, \& Assad, 1990; Rieber \& Parmley, 1995), and electrical circuits (Carlsen \& Andre, 1992; Chambers et al., 1994). Sometimes the single simulation is compared to expository instruction (Rieber \& Parmley, 1995), but quite often a comparison is made between a simulation embedded in a curriculum or expository instruction and the curriculum or expository instruction as such (Carlsen \& Andre, 1987; Chambers et al., 1994; Grimes \& Willey, 1990; Rieber et al., 1990; Rivers \& Vockell, 1987). Also, in some cases, the expository instruction to which the simulation is compared is "enhanced", e.g., by "conceptual change features" (Chambers et al., 1994) or by questions (in one condition of Rieber et al., 1990). As an overall picture, favorable results for simulation based learning are reported in the study by Grimes and Willey (1990), and no difference between simulation 
based learning and expository teaching is reported by Carlsen and Andre (1992), and Chambers et al. (1994). A mixture of favorable and no difference results was found between several sub-studies by Rivers and Vockell (1987). In Rieber et al. (1990) the group of students receiving a simulation in addition to a tutorial scored higher on a test measuring "application of rules" than the tutorial only group, but scored at the same level as a tutorial group that received additional questions while learning. In Rieber and Parmley (1995) subjects who received only an unstructured (pure) simulation fell short of the performance of subjects receiving a tutorial.

The general conclusion that emerges from these studies is that there is no clear and univocal outcome in favor of simulations. An explanation why simulation based learning does not improve learning results can be found in the intrinsic problems that learners may have with discovery learning. In the above mentioned studies, Chambers et al. (1984), for example, analyzed the videotapes of students working with the simulation and noticed that students were not able to deal with unexpected results and that students did not utilize all the experimenting possibilities that were available. Also studies that compared learning behavior of successful and unsuccessful learners in simulation learning environments (e.g., Schauble, Glaser, Raghavan, \& Reiner, 1991) have pointed to specific shortcomings of learners. For this reason, in a number of studies, additional instructional measures are suggested to help 
Scientific Discovery Learning with Computer Simulations

learners overcome the problems that they may have with

scientific discovery learning.

In the discussion that follows, we provide an overview of potential problems with scientific discovery learning with simulations and search for guidance in dealing with these problems. In addition, we examine studies that have looked at the effect of combining simulations with various instructional support measures for learners. The literature that serves as the framework for this discussion comes from several sources. First, we began with documents from two relevant research programs - Laboratory for Research and Development in Cognition and Carnegie Mellon (e.g., Klahr and Dunbar, 1988; Reimann, 1991; Schauble et al., 19991; Shute \& Glaser, 1990). Not only were these documents useful in organizing this review, but they were also valuable resources in locating additional studies of scientific discovery learning with computer simulations. Next, we searched on-line retrieval systems (e.g., Educational Resources Information Center) using the main descriptor of "computer simulation(s)". This rendered (in the June 1997 version of ERIC) 2073 writings. Since the combination with "discovery (learning or processes)" gave a set of papers that did not contain some relevant papers we knew of, we examined the ERIC descriptions of all 2073 papers. We also solicited papers that had been presented at national and international conferences that address the topic of computer simulations (e.g., American Educational Research Association, European 
Association for Research on Learning and Instruction, World Conference on Artificial Intelligence in Education, and the International Conference on Intelligent Tutoring Systems), and examined the contents of edited volumes published over the last five years. Furthermore, we engaged in a physical search of selected research journals likely to publish studies dealing with computer simulations. These journals included the Journal of Research in Science Teaching, Computers \& Education, Journal of Computer-Based Instruction, Instructional Science, and the Journal of the Learning Sciences. For our topic of discovery learning with computer simulations we found four types of papers. First, we found papers that we would like to call engineering studies, in which a learning environment is merely described. The second type of papers concerns conceptual papers that deal with theoretical issues on discovery learning and simulations. Thirdly, we found papers in which empirical data were gathered (through e.g., log files or thinking aloud procedures) on discovery learning processes. In the fourth type of papers experimental studies are described in which simulation environments are evaluated against expository teaching, or in which different versions of basically the same simulation environment are compared. Our selection process was guided by the following criteria. First, we excluded experimental papers if they did not use carefully controlled experimental designs, and/or did not have well-defined performance measures. Secondly, we targeted original studies 
Scientific Discovery Learning with Computer Simulations

for this review and excluded subsequent writings that merely recast a previous study or repeated the same argumentation. Problems that Learners Encounter in Discovery Learning In the following subsections we identify a number of characteristic problems that learners may encounter in discovery learning, and classify them according to the main discovery learning processes: hypothesis generation, design of experiments, interpretation of data, and regulation of learning. Hypothesis Generation

Finding new hypotheses is generally recognized as a difficult process (Chinn \& Brewer, 1993), that clearly distinguishes successful and unsuccessful learners (Schauble, Glaser, et al., 1991). An important problem here is that learners (even university students) simply may not know what a hypothesis should look like. Njoo and De Jong (1993a) assessed the "validity" of learning processes of 91 students of mechanical engineering working on a simulation on control theory. They observed the syntactical correctness of the learning processes that students wrote down on "fill-in forms". For example, for the process of generating a hypothesis they examined whether it consisted of variables and a relation between them, not if the hypothesis was correct in the domain. Njoo and De Jong found an average score of 42\% correctness of processes, and even lower scores for the process of generating hypotheses.

A second problem is that learners may not be able to state 
or adapt hypotheses on the basis of data gathered. Klahr and Dunbar (1988) found that in 56\% of observed cases students failed to draw the right conclusions from disconfirming experiments: i.e., hypotheses were retained incorrectly on the basis of a negative experimental result. Other studies also emphasize the resistance of learners to theoretical change. Chinn and Brewer (1993) present seven typical learners' reactions to anomalous data, of which only one is the adaptation of the theory on the basis of the data. They give a large number of studies in which it was found that learners ignored anomalous data (see also Chambers et al., 1994), in which they reject them, hold them in abeyance, reinterpret them and retain the theory, or reinterpret them and make marginal changes to the theory (Chinn \& Brewer, 1993, p. 4). Also Dunbar (1993) found evidence in his studies that subjects have an overall difficulty with dropping an original goal, which leads to a persistence of keeping an hypothesis and not stating a new one. As an explanation, Dunbar (1993) mentions what he calls the "unableto-think-of-an-alternative-hypothesis" phenomenon, meaning that subjects stick to their current hypothesis (despite conflicting evidence) simply because they have no alternative. These findings may lead to the general assumption that people have a strong tendency to keep their original ideas. However, Klahr and Dunbar (1988) also found a reverse effect, learners rejecting hypotheses without a disconfirming outcome of an experiment. This general problem of translating data into_theory 
is illustrated in a study by Kuhn, Schauble, and Garcia-Mila (1992) who found that subjects (ten year olds) changed their ideas on the causality of a domain variable many times (10 to 11 times) during an experimentation session. The frequent change of ideas can partly be explained by the fact that subjects in Kuhn et al.'s study employed a large repertoire of what Kuhn et al. call "invalid inferences". So, subjects for example made inferences about causality on a single instance or made inferences about a variable that had not been changed in two experiments. One aspect that may well influence the ability to adapt hypotheses on the basis of data is the distance between the theoretical variables and the variables that are manipulated in the simulation (Van Joolingen \& De Jong, 1997). Glaser et al. (1992) assert that in the environments Voltaville (on d.c. circuits) and Refract (on refraction of light) it is easier for subjects to see the relation between their manipulations of lenses, distances, resistances etc. and the characteristics of the theoretical model than in an environment such as smithtown (on economics) where a larger distance exists between theoretical variables and the variables that can be manipulated in the simulation.

A third problem in stating hypotheses is that learners can be led by considerations that not necessarily help them to find the correct (or best) theoretical principles. Van Joolingen \& De Jong (1993) describe a phenomenon that they called fear of rejection. In an analysis of the use of a so-called "hypothesis 
scratchpad" by 31 students they found that subjects tend to avoid hypothesis that have a high chance of being rejected, for example hypotheses in which the relation has a high level of precision. A similar phenomenon was described by Klayman and Ha (1987), and by Klahr, Fay, and Dunbar (1993).

\section{Design of Experiments}

A crucial aspect of scientific discovery is the design of experiments that provide information for deciding upon the validity of an hypothesis. In case that a learner does not yet have a hypothesis, well designed experiments can be used to generate ideas about the model in the simulation. Klahr, Dunbar, and Fay (1991) identified a number of successful heuristics for experimentation in the BigTrak environment (which concerns the operation of a programmable robot). For experiment design they mention: design simple experiments to enable easy monitoring, design experiments that give characteristic results, focus on one dimension of a hypothesis, exploit surprising results, and use the a priori strength of a hypothesis to choose an experimental strategy (Klahr et al., 1991, pp. 388-391). In literature we find a number of phenomena that point to learners who use poorly designed experiments.

The first phenomenon, confirmation bias, is the tendency to seek for information that confirms the hypothesis they have, instead of trying to disconfirm the hypothesis. In classical experiment Wason's (1960) found confirmation bias for a rule discovery (2-4-6) task in which seeking confirming evidence is 
not the best strategy to use (Klayman \& Ha, 1987). Dunbar

(1993) showed, in a simulation environment, that some students have a strong inclination to search for evidence that support their current hypothesis, and that this inclination may prevent them to state an alternative hypothesis, even when they are confronted with inconsistent evidence. In an experiment with a simulation on the spread of an influenza epidemic Quinn and Alessi (1994) found that only in a small number of cases (one out of six in a sample of 179 subjects) students conducted experiments with the intention of "eliminating" hypotheses. In their study students were asked before running an experiment to choose the purpose of the experiment from a series of alternatives presented.

The second phenomenon describes learners who design inconclusive experiments. One of the best known examples is described in Wason's card turning experiment (Wason, 1966). This phenomenon, that is analogous to the phenomenon of confirmation bias, shows that subjects do not always behave as "logical thinkers", and do not perform the most effective actions to test an hypothesis. In the context of discovery learning with simulations, Glaser et al. (1992) point to a frequently observed phenomenon that learners tend to vary too many variables in one experiment, resulting in that they cannot draw any conclusions from these experiments. Reimann (1991) observed in the domain of optics that subjects perform poorly designed experiments, that do not allow them to draw univocal 
conclusions. In two studies, Van Joolingen and De Jong (1991b; 1993) found that learners often designed experiments in which variables were manipulated which had nothing to do with the hypothesis they were testing. The percentage of effective experiments could be as low as 22\%. Shute and Glaser (1990) and also Schauble, Glaser, et al. (1991) report that unsuccessful learners do not gather sufficient data before drawing conclusions.

A third phenomenon is that subjects show inefficient experimentation behavior. For example, Kuhn et al.(1992) found that subjects did not use the whole range of potential informative experiments that were available, but only a limited set, and moreover designed the same experiment several times.

A fourth phenomenon describes learners that construct experiments that are not intended to test a hypothesis. Schauble, Klopfer, and Raghavan (1991) identified what they have called the "engineering approach", which denotes the attitude to create some desirable outcome instead of trying to understand the model. An engineering approach, as compared to the scientific approach, leads to a much less broad search and to a concentration on those variables where success is expected, and as a consequence this approach may prevent learners from designing experiments that provide sufficient and well organized data for discovering all relevant domain relations. This engineering approach was also found by Schauble, Glaser, Duschl, Schulze, and John (1995), and Njoo 
and De Jong (1993a). A comparable phenomenon was found by White (1993) who reported that students created experiments that were "fun" (students had worked with games in White's simulation environment) instead of experiments that provided insight into the model.

\section{Interpretation of Data}

Once having performed correct experiments, data that come from these experiments needs to be interpreted before the results from the experiments can be translated into hypotheses on the domain. According to Schauble, Glaser, et al. (1991) successful learners are more proficient in finding regularities in the data than unsuccessful learners. Klahr et al. (1993) found that subjects made misencodings of experimental data ranging from a mean of 35\% of at least one misencoding, to a high 63\% depending on the type of actual rule involved. And indeed, as Klahr et al. state: "Compared to the binary feedback provided to subjects in the typical psychology experiment, realworld evidence evaluation is not so straightforward" (p. 114). They report that, in the case of misinterpreting data, this most likely resulted in a confirmation of the current hypothesis, thus suggesting that the hypothesis that a subject holds may direct the interpretation of data (see also Chinn \& Brewer, 1993, and Kuhn et al., 1992).

Also the interpretation of graphs, a frequently needed skill when interacting with simulations, is clearly a difficult process. Linn, Layman, and Nachmias (1987) compared a group of 
students who worked with "microcomputer-based laboratories"

(MBL) with students from traditional classes. In the MBL students carried out experiments in the physics field of heat and temperature. Output of these experiments was given in the form of dynamically generated graphs. Linn et al. (1987) found that students graphing abilities increased because of working with the MBL, but that on the more complicated graphing skills (for example comparing different graphs) difficulties still existed after the MBL course. Mokros and Tinker (1987) placed students in computer labs, where they could generate graphs on the basis of experiments, and were encouraged to make graphical predictions. They found that the problems that children initially had with interpreting graphs, quickly disappeared. $\underline{\text { Regulation of Discovery Learning }}$

For regulative processes it is frequently reported that successful learners use systematic planning and monitoring, whereas unsuccessful learners work in an unsystematic way (e.g., Lavoie \& Good, 1988; Simmons \& Lunetta, 1993). Shute and Glaser (1990) claim that successful learners plan their experiments and manipulations to a greater extent, and pay more attention to data management issues. Glaser et al. (1992) report that successful discoverers followed a plan over experiments, whereas unsuccessful ones used a more random strategy, concentrating at local decisions, which also gave them problems to monitor what they had been doing (see also Schauble, Glaser, et al., 1991). Though Glaser et al. (1992) 
Scientific Discovery Learning with Computer Simulations

mention persistence to follow a goal as a characteristic of good learners, these successful subjects also were ready to leave a route when it apparently would not lead to success. Goal setting is also reported as a problem (for subjects with low prior knowledge) by Charney, Reder, and Kusbit (1990). In a more general way Veenman and Elshout (1995) found that, over a number of studies, individuals with a high intellectual ability showed a better working method than individuals with a low intellectual ability, but also that working method had its own contribution to learning outcome on top of intellectual ability. For the process of monitoring differences between successful and unsuccessful learners are reported by Lavoie and Good (1988) who found that good learners make more notes during learning, and by Schauble, Glaser, et al. (1991) who found a more systematic data recording for successful learners. Combining Simulations and Instructional support

The previous section presented a number of characteristic problems in scientific discovery learning. A number of researchers and designers have recognized these problems and provided, in line with the developments in concept discovery learning (see e.g., Mayer, 1987), learners with support for learning with a simulation. In the current section we summarize a number of methods to support learners in the discovery process. The first means of support we describe is to provide the learner with direct access to domain information. Subsequently, we present support measures that aim to support 
Scientific Discovery Learning with Computer Simulations

the learner in specific discovery processes.

Direct Access to Domain Knowledge

A frequently uttered claim about learning with simulations is that learners should already know something before discovery learning is to become fruitful. Insufficient prior knowledge might be the cause that learners do not know which hypothesis to state, can not make a good interpretation of data, and move to unsystematic experimentation behavior (Glaser et al., 1992; Schauble, Glaser, et al., 1991). Several authors have introduced access to extra information as a support measure in a simulation environment, quite often in the form of a (more or less sophisticated) hypertext/hypermedia system (Glaser, Ragahvan, \& Schauble, 1988; Lajoie, 1993; Shute, 1993; Thomas \& Neilson, 1995). Shute (1993) described an ITS on basic principles of electricity in which learners could ask for definitions of concepts (e.g. ammeter, ampere, charge, circuit, current...) by selecting a term from a menu and follow hypertext links. Shute (1993) reports positive effects of use of this on-line hypertext dictionary on a composite post-test measuring declarative and conceptual knowledge, problem solving, and transfer of knowledge and skills. A number of authors point to the critical aspect of timing of the availability of information. Berry and Broadbent (1987) found that providing information at the moment it is immediately needed by the learner is much more effective than providing all information needed before interaction with a simulation. In 
Leutner's (1993) study, a simulation was used of a fairly complex agricultural system in which the students' assignment was to optimize the agricultural production. Leutner provided students with information (consisting of domain concepts, facts, rules, and principles) before interacting with a simulation, or information (background information on system variables) while interacting with the simulation. Leutner found that permanently available information helped learners to acquire domain knowledge (knowledge of concepts, rules, and principles), but that information provided before the simulation was not effective. For acquiring functional knowledge (ability to optimize the outcome of the simulation) the same pattern was found, but here results are less direct since providing the information before or during the interaction with the simulation was combined with more or less elaborate experimentation advice. Also, Elshout and Veenman (1992) report that subjects who received domain information before working in a simulation environment (on heat theory) did not profit from this information.

Information cannot only be provided by the learning environment, but must also be invoked from learners' memory. Support measures can stimulate learners to confront their prior knowledge with the experimental outcomes. In order to achieve this, Lewis, Stern, and Linn (1993) provided learners with an electronic notation form to note down "everyday life examples" of phenomena they observed in a simulation environment (on 
Scientific Discovery Learning with Computer Simulations

thermodynamics) .

Support for Hypothesis Generation

Hypothesis generation is a central process in discovery learning. Several studies have created support to overcome the problems that learners have with this process. Smithtown (Shute \& Glaser, 1990) offers the learner support for hypothesis generation by means of a hypothesis menu. This menu consists of four windows which present parts of a hypothesis e.g., variables, verbs to indicate change, and connectors. A similar means of support is a hypothesis scratchpad (Van Joolingen \& De Jong, 1991b; 1993). Here, learners are offered different windows for selecting variables, relations, and conditions. These two approaches offer learners elements of hypotheses that they have to assemble themselves. A more directive support for creating hypotheses can be found in CIRCSIM-TUTOR (Kim, Evans, Michael, \& Rovick, 1989), an ITS in the domain of medicine which treats problems associated with blood pressure where students are asked to state qualitatively what will happen to seven components of the cardio-vascular system. To be able to write this down learners are offered a predefined spreadsheet. One step further is to offer learners complete hypotheses. In "Pathophysiology Tutor" (PPT) (Michael, Haque, Rovick, \& Evens, 1989) learners can select from a list of predefined hypothesis, ordered in nested menus providing lists of hypotheses in the field of physiopathology. Njoo and De Jong (1993a; 1993b) have used similar techniques. They conclude that offering predefined 
hypothesis to learners positively influences the learning process and the performance of learners. Quinn and Alessi (1994) forced students to write down, before experimenting, in a simulation a single most plausible hypothesis, or a list of more than one plausible hypotheses. The idea is that having more hypotheses available will lead to a strategy of elimination, which could be better than focusing on one hypothesis at a time. Their data showed that the multiple hypothesis strategy indeed lead to more effective performance (reaching a required state of the simulation), but only if the complexity of the simulation was low. At higher levels of complexity in the simulation no advantage of the multiple hypotheses strategy over the single hypothesis strategy could be found. The higher effectiveness of the multiple hypotheses strategy could have been enhanced by the fact that one of the variables included had a counterintuitive result. Support for the Design of Experiments

To support a learner in designing experiments the learning environment can provide experimentation hints. In Rivers and Vockell (1987) some examples of such hints are given, like "it is wise to vary only one variable at a time". They provided learners with such general experimentation hints before students worked with computer simulations. This did not effect the learning outcome, but it had an affect on the students' experimentation abilities. Hints can also be generated dynamically on the basis of the actual experimentation behavior 
of learners. Hints are then presented if a learner displays non-optimal learning behavior. An example of a system containing this type of hints is Smithtown (Shute \& Glaser, 1990). Leutner (1993) studied the effect of providing learners with adaptive advice of this kind. He found that if the advice has a limited character it helps to increase the learner's domain knowledge, but hinders the acquisition of functional knowledge. After giving more detail to the advice it also helped to increase the functional knowledge, though the effect is less clear since it was combined with giving extra domain information.

\section{Support for Making Predictions}

While a hypothesis is a statement on the relations between variables in a theoretical model, a prediction is a statement on the value(s) of a dependent variable under the influence of values of the independent variable(s) as they can actually be observed in the simulation. One specific way to help learners express predictions is to give them a graphing tool in which they can draw a curve that depicts the prediction. Lewis et al. (1993) provided learners with such a tool. Feedback is given to learners by drawing the correct curve in the same diagram in which the learner's prediction was drawn. Tait (1994) describes a similar mechanism, but in his case feedback also includes explanations of the differences between the system's and the learner's curve. Reimann (1991) who describes an environment on the refraction of light provided learners with the opportunity 
Scientific Discovery Learning with Computer Simulations

to give predictions at three levels of precision: as numerical data, as a drawn graph, and as an area in which the graph would be located.

Support for Regulative Learning Processes

Regulative processes are the processes that manage the learning process. Regulative aspects such as "planfulness and systematicity" are regarded to be central characteristics of successful discovery learning (Glaser et al., 1992; Schauble et al., 1995). The two most central regulative processes are planning and monitoring (De Jong \& Njoo, 1992). Planning and monitoring are both supported by introducing model progression in the simulation environment. Next to model progression, we found specific measures for supporting planning or monitoring. Finally, regulative processes can be supported by structuring the discovery process.

Model progression. The basic idea behind model progression is that presenting the learner with the full complexity of the simulation at once may be too overwhelming. In model progression the model is introduced gradually, step by step. White and Frederiksen's (1989; 1990) work on QUEST is one of the best known examples where the idea of model progression has been applied. QUEST treats electrical systems and models of electrical circuits in QUEST differ in their order (qualitative or quantitative models), degree of elaboration (number of variables and relations between variables), and perspective. While learning with QUEST, learners are confronted with models 
Scientific Discovery Learning with Computer Simulations

that advance from a qualitative to a quantitative nature, that are more elaborated, and that transform from a functional to a physical perspective. In this respect the instructional sequence follows the (assumed) transition from a novice knowledge state to an expert one. As far as we know, no controlled evaluation of QUEST has been undertaken. Model progression in which the model increases in complexity for the learner was studied in Swaak, Van Joolingen, and De Jong (1996). SETCOM is a simulation on harmonic oscillation where the model develops from free oscillation, through damped oscillation to oscillation with an external force. Swaak et al. (1996) found that model progression was successful in enlarging the students' intuitive knowledge (but not their conceptual knowledge) as compared to an environment without model progression. In a study in a different domain, but within the same type of environment, De Jong et al. (1995) could not find effects of providing learners with model progression on top of giving them assignments. Quinn and Alessi (1994) performed a study in which students had access to a simulation (on the spread of a disease within a population) with four input variables. One group started off with access to all four input variables, one group exercised with three variables before proceeding to the full simulation, and the last group started with having access to two variables, proceeding to three and ending with all four. In all cases students had to minimize the value of one of the output variables. Their data revealed that 
model progression had no overall positive effect on performance. Model progression, however, proved to be less efficient than providing the students directly with full complexity. It should be noted, that the domain that was used by Quinn and Alessi, was quite simple: the variables in the model did not interact. In another study on a more complex simulation of a multimeter, Alessi (1995) found that gradually increasing the level of complexity of the interface was beneficial for initial learning and for transfer. Also, Rieber and Parmley (1995) found, in the area of Newtonian motion, that subjects learning with a simulation that presented an increasing control over variables, scored significantly higher at a test measuring application of rules, than subjects who could exercise control in its full complexity from the start.

Planning support. Planning support may, as Charney et al. (1990) have postulated, be especially helpful for subjects who have low prior knowledge. Planning support takes away decisions from learners and in this way helps them in managing the learning process. Support for planning can be given in different ways. Already quite early in the use of simulations for scientific discovery learning, Showalter (1970) recommended to use questions as a way to guide the learner through the discovery process. His questions (e.g. "Do rats ever reach a point at which they don't learn more?", p. 49) focused the learners attention to specific aspects of the simulation. Zietsman and Hewson (1986) used similar types of questions in 
conjunction with a simulation on "velocity", and Tabak, Smith, Sandoval, and Reiser (1996) have added such questions with the aim of setting goals in a biological simulation. White (1984) helped learners to set goals in a simulation of Newtonian mechanics by introducing games. Games, as White uses them, ask learners to reach a specific state of the simulation (e.g. to get a spaceship in the simulation around a corner without crashing into any walls (p. 78). In an experiment white found that learners who learned with a simulation that contained games, outperformed learners who worked with the pure simulation on a test of qualitative problems (asking questions of the form "What would happen if ..?" or "How could one achieve...?" (p. 81)). Also, in the ThinkerTools environment (White, 1993) games are used in a similar context as in White (1984). De Jong et al. (1994) describe different types of assignments that can be used in combination with simulations, among others investigation assignments that prompt students to find the relation between two or more variables, specification assignments that ask students to predict a value of a certain variable, and explicitation assignments that ask the student to explain a certain phenomenon in the simulation environment. In De Jong et al. (1995) using a simulation on collisions, Swaak et al. (1996) using a simulation on harmonic oscillation, and De Jong, Härtel, Swaak, and Van Joolingen (1996) using a simulation on the physics topic of transmission lines it was found that students (who were free to choose) used assignments very frequently, and 
that using assignments had a positive effect on gaining what they call "intuitive" knowledge.

Monitoring support. Support for monitoring one's own discovery process can be given by overviews of what has been done in the simulation environment. Reimann (1991) provided learners in Refract with a notebook facility for storing numerical and nominal data from experiments. Data in the notebook could be manipulated so that experiments could be sorted on values for a specific variable, experiments could be selected in which a specific variable has a specified value, and an equation could be calculated over experiments. Also the student could replay experiments from the notebook. Similar notebook facilities are present in Smithtown (Shute \& Glaser, 1990) and Voltaville (Glaser et al., 1988). In SHERLOCK learners can receive upon request an overview of all the actions they have taken so far (Lesgold, Lajoie, Bunzo, \& Eggan, 1992). Schauble, Raghavan, and Glaser (1993) presented monitoring support that not only provided an overview of students' actions, but also offered the opportunity to group actions under goals, and to ask for an "expert view" that gives the relevance of the student's actions in the context of a specific goal (e.g. to find the relation between two variables). This support in fact combines monitoring and planning support. In all the examples presented here, learners have to select previous experiments for comparison from the complete set of experiments themselves. Reimann and Beller 


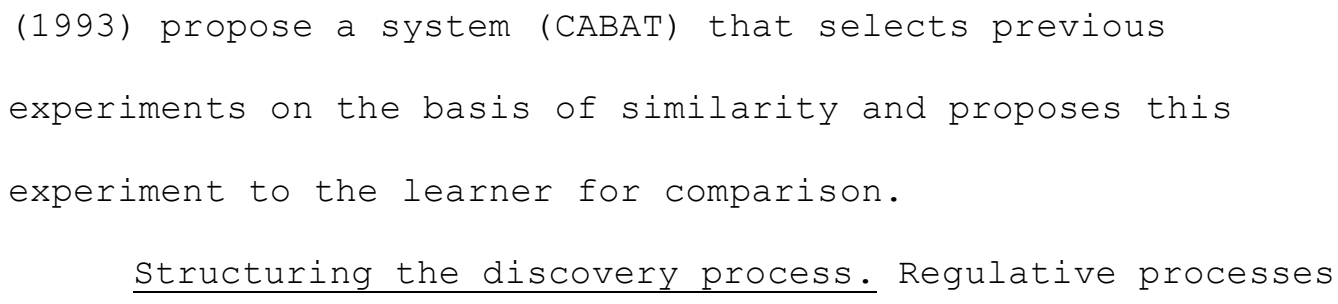


The other half received no guidance. The simulation used was in the field of economics, a jeans factory for which profit should be maximized. On a knowledge test in which students had to make predictions in new situations, the guidance group outperformed the non-guidance group. White (1993) in her ThinkerTools environment forced subjects to follow a four phases sequence of activities of "asking questions, doing experiments, formulating laws, and investigating generalizations" (White, 1993, p. 53), and provided more detailed indications in each phase. White found a clear advantage for a simulation based curriculum compared to a traditional curriculum on a test that measured qualitative predictions in real-world situations. In a number of experiments Veenman and Elshout compared the learning behavior and learning result of learners working with a "structured" and an "unstructured" simulation environment. In the "unstructured" simulation subjects did not receive any instructional guidance. In the structured (or "meta-cognitive mediation") condition, subjects received "task assignments" and were prompted to "paraphrase the question, to generate a hypothesis, to think out a detailed action plan, and to make notes of it", Also, after they had performed a series of actions, they were "requested to evaluate their experimental outcomes", to "draw a conclusion elaborating on the subject matter, and to make notes" (e.g., Veenman, Elshout, \& Busato, 1994, p. 97). The domains involved were simple electrical circuits, heat theory, and statistics. In an overall analysis 
of the data of four of their studies Veenman and Elshout (1995) found no overall effect of structuring the environment. At a more detailed level they found evidence that low intelligence subject with a poor working method profit from structuring the environment, whereas this is not true for low intelligent subjects with a good working method, and not so for high intelligent subjects regardless of their working method. In this overall analysis several performance measures (including test for factual knowledge and problem solving tasks) were combined into a single performance score.

We found two studies in which a comparison was made between a structured simulation environment and traditional, expository, instruction. Lewis et al. (1993) required learners to make predictions before doing an experiment, and to write down "graph comparisons" and "conclusions" after the experiment. Additionally, learners were encouraged to write down "every day examples", "important points", "confusion about" and "example of concept" notes (Lewis et al., 1993, p. 48). This was done in an electronic form using a "post-it" metaphor. Lewis et al. found that a higher percentage of students was able to give correct answers to items requiring a fundamental understanding of the difference between heat and temperature as compared to students following the traditional curriculum in the preceding year. In Smithtown (Shute \& Glaser, 1990) learners are taken by the hand and led through a fixed sequence of actions, that is a little less strict than, for example the sequence from Lewis et 
al. (1993). In Smithtown, learners are only asked if they want to make a prediction before experimentation and they are not forced to do this. Smithtown not only includes structuring, but also a wealth of other supportive measures. An evaluation of Smithtown, using a test that required recall of concepts, failed to show an advantage of learning with smithtown over a traditional lesson (though learning with Smithtown was far more efficient).

\section{Conclusion and Discussion}

In this study we gave an overview of studies in scientific discovery learning with computer simulations of conceptual domains. From studies that empirically examined the discovery learning process we can conclude that a number of specific skills are needed for a successful discovery. Generally, one can say that successful discovery learning is related to reasoning from hypotheses, to applying a systematic and planned discovery process (like systematic variation of variable values), and to the use of high quality heuristics for experimentation. These skills may have a general character, but can also be more closely related to a domain (Glaser et al., 1992). Several characteristic problems in the discovery process were identified. For the process of hypothesis generation weaknesses are choosing hypotheses that seem "safe", and the weak transformation of data into a hypothesis, both when the data are confirming and when they are disconfirming. For designing experiments we found reports on learners who design 
inconclusive experiments, who show inefficient experimentation behavior, who follow a confirmation bias, and who apply an engineering instead of a scientific approach. Furthermore, learners quite often have trouble with the interpretation of data as such. A final problem that is reported is that students are not very capable in regulating the learning process which is expressed in unstructured behavior drifted by local decisions without overall plan, and in insufficient monitoring of the learning process.

We also examined instructional measures that are used together with simulations. Quite a few of the studies in which instructional measures were introduced were still in the engineering phase and did not evaluate the effect of the instructional measure in a controlled manner. Other studies in which the effect of adding instructional measures were evaluated, used combinations of instructional measures so that the effect of a specific measure could not be traced. On the basis of the remaining studies three individual instructional measures can be seen as measures that have the promise of having a positive influence on learning outcomes. First, providing direct access to domain information seems effective as long as the information is presented concurrently with the simulation so that the information is available at the appropriate moment. Secondly, providing learners with assignments (or questions, exercises, or games) seems to have a clear effect on the learning outcome. Thirdly, learners who use 
an environment that includes model progression perform better than learners using the same environment without model progression, though it seems that the model needs to be sufficiently complex to reach this effect. For other individual measures the evidence is not substantial enough to warrant general conclusions (e.g., hypothesis support, experimentation hints, monitoring tools, prediction support). Finally, a number of studies on structuring the environment show that this may lead to more effective learning than using an unstructured environment, though it should be noted that structuring the environment in all these studies not only involved dividing up the learning process in distinguished steps, but also included other instructional measures.

A crucial aspect of scientific discovery learning is the instructional goal for which it is used. Following the original ideas on discovery learning, it is frequently claimed that scientific discovery learning leads to knowledge that is more intuitive and deeply rooted in a learner's knowledge base (Berry \& Broadbent, 1984; Laurillard, 1992; Lindström, Marton, Ottosson, \& Laurillard, 1993; Swaak \& De Jong, 1996) that has a more qualitative character (White, 1993), and that results of simulation based learning are only properly measured by "tests of application and transfer" (Thomas \& Hooper, 1991, p. 500). Support for this claim is found in studies by Berry and Broadbent (1984) who showed that while simulations can be effective in training the ability to acquire a certain state in 
the simulation, this does not necessarily mean that the associated conceptual knowledge is learned as well. This lack of a relation between "explicable" knowledge and "functional knowledge" was also found for a simulation on business by Anderson and Lawton (1992), Newtonian motion (with children) by Flick (1990), on kinematics by McDermott (1990), on collisions (De Jong et al., 1995; Whitelock et al., 1993), on a complex agricultural simulation (Leutner, 1993), in an economics subdomain (Mandl, Gruber, \& Renkl, 1994), for acceleration and velocity (Rieber et al., 1996; Rieber, 1996), and on harmonic oscillations (Swaak et al., 1996). In the studies that we cited in this overview we find support for the importance of "intuitive" or "deep" knowledge for discovery learning. In studies that compared simulation with expository teaching, Grimes and Willey (1990), for example, used a test with items that asked for "recognition and understanding", "explicit application", or "implicit application". In their study, the simulation group, having an overall advantage over the control group, was specifically successful in items measuring implicit application. In Carlsen and Andre (1992), simulation groups had no higher score on the posttest than a no simulation group, but when the items were analyzed (by looking at the alternatives chosen) on the mental model that students had acquired, students from the simulation groups showed more advanced models. Rieber et al. (1990) used a test to measure the ability to apply rules from the domain. The simulation group used 
significantly less time in answering the post-test questions than a group receiving a tutorial enhanced with questions. According to Rieber et al. (1990) this points to more deeply processed knowledge. Again, in studies where different versions of simulation environments were compared we see an effect of the type of knowledge test used. In De Jong et al. (1995) and Swaak et al. (1996) results were tested by a test asking for definitional knowledge and also by a test measuring 'intuitive" knowledge. In this test subjects had to predict what would happen after a change was introduced in a situation, and they had to make this prediction as quickly as possible (see also Swaak \& De Jong, 1996). Though learners improved in definitional knowledge when learning with the simulation environments (that also contained expository information), the gain in intuitive knowledge was larger, and also differential effects of simulation environments only came out on the intuitive knowledge test. Finally, the type of knowledge test used also seems to play a role in the studies that compared structured simulation environments with unstructured ones or with the normal curriculum. In Linn and Songer (1991), and Lewis et al. (1993) a test was used that measured qualitative distinctions between central concepts, Njoo and De Jong used items that measured qualitative insight, and Gruber et al. (1995) and White (1993) used tests in which predictions had to be given (like in De Jong et al., 1995, and Swaak et al., 1996). All these studies showed an advantage for the structured simulation environments. In 
Veenman and Elshout (1995) where a combination of qualitative and definitional knowledge was used for a test, no overall effect of structuring the environment was found, with an exception for specific group of learners. Finally, in the evaluation of Smithtown (Shute \& Glaser, 1990) no difference between the effectivity of a structured simulation environment and a traditional lesson could be found, but here a test measuring recall of concepts was applied. Advantages of simulations seem clear when the instructional goal is the mastery of discovery skills. In Rivers and Vockell (1987) not only domain knowledge was assessed but also discovery abilities were measured by a number of general test (e.g. the WatsonGlaser Critical Thinking Appraisal) and by analyzing the trend in scores on a domain pretest. They conclude that students from the simulation curricula outperformed the control subjects, especially if the simulations contained guidance in the form of hints that pointed to good discovery behavior (see also Faryniarz \& Lockwood, 1992, and Woodward, Carnine, \& Gersten (1988) .

At present we see a further development of environments that invite learners to engage in self directed (discovery) learning and that provide support tools for the learning process (see, for example, Suthers, Weiner, Connelly, \& Paolucci, 1995). A further and deeper analysis of problems that learners encounter in discovery learning and a further evaluation of specific ways to support learners is, therefore, 
in our view, the principal item on the research agenda in this area. Studies should aim to find out when and how to provide learners with means to overcome their deficiencies in discovery learning, in other words how to provide "scaffolding" for the discovery learning process. For these evaluation studies there are three additional points of interest. The first one is that introducing additional support tools is not only meant to enable the learner to perform certain actions, but can also be used to prevent cognitive overload (Glaser et al., 1988, p. 63). However, some instructional measures may also raise cognitive load, by introducing more complexity into the environment. Gruber et al. (1995), for example, suggest a raise in cognitive load when introducing multiple perspectives in a simulation environment. Further research on support measures should take into consideration the effects of additional support measures on cognitive load (see e.g., De Jong et al., 1995; Swaak et al., 1996). A second aspect of support tools is that in learning environments these tools can also be used for unobtrusive measures, as was already recognized by Glaser et al. (1988) in the design of Voltaville. For example, in SHERLOCK (Lesgold et al., 1992) the student goes through the diagnostic problem solving process by choosing from menu's of actions. On the one hand this helps the student in the planning process, on the other hand this helps the researcher (the system) to assess the student's intentions. In the SHERLOCK environments information from this "planning tool" for the 
learner is utilized for generating adequate hints. Van Joolingen (1995) describes some principles of how information gathered through a hypothesis scratchpad can be used for assessing the learner's actual state of knowledge. The third point of interest is that the place of simulations in the curriculum should be investigated. Lavoie and Good (1988) suggest that a "Piagetian" approach should be used, which implies that simulations are introduced in a first phase of learning where exploration is allowed, that concepts are formally introduced later, finally followed by concept application (see also Brant et al., 1991; White, 1993). This suggests a potential use of computer simulation that differs from the classical hypothesis driven approach. Only after sufficient research results along the lines sketched in this section will be available, an appropriate design theory for instructional simulations may arise. Current attempts, though interesting, are necessarily fragmentary and incomplete (see e.g., Thurman, 1993). Based on such a theory, discovery learning with simulations can take its place in learning and instruction as a new line of learning environments based on technology where more emphasis is being given to the learner's own responsibility. 
Scientific Discovery Learning with Computer Simulations

References

Alessi, S.M. (1995, April). Dynamic vs. static fidelity in a procedural simulation. Paper presented at the Annual Meeting of the American Educational Research Association, San Francisco, CA.

Alessi, S.M., \& Trollip, S.R. (1985). Computer based instruction, methods and development. Englewood Cliffs, NY: Prentice-Hall.

Anderson, P.H., \& Lawton, L. (1992). The relationship between financial performance and other measures of learning on a simulation exercise. Simulation \& Gaming, 23, 326-340.

Bangert-Drowns, R., Kulik, J., \& Kulik, C. (1985). Effectiveness of computer-based education in secondary schools. Journal of Computer Based Instruction, 12 , 59-68.

Berry, D.C., \& Broadbent, D.E. (1984). On the relationship between task performance and associated verbalizable knowledge. The Quarterly Journal of Experimental Psychology, $\underline{36 \mathrm{~A}}, 209-231$.

Berry, D.C., \& Broadbent, D.E. (1987). Explanation and verbalization in a computer-assisted search task. The Quarterly Journal of Experimental Psychology, 39A, 585-609. Brant, G., Hooper, E., \& Sugrue, B. (1991). Which comes first the simulation or the lecture? Journal of Educational Computing Research, ㄱ, 469-481.

Bruner, J.S. (1961). The act of discovery. Harvard Educational $\underline{\text { Review, }}$ 31, 21-32. 
Scientific Discovery Learning with Computer Simulations

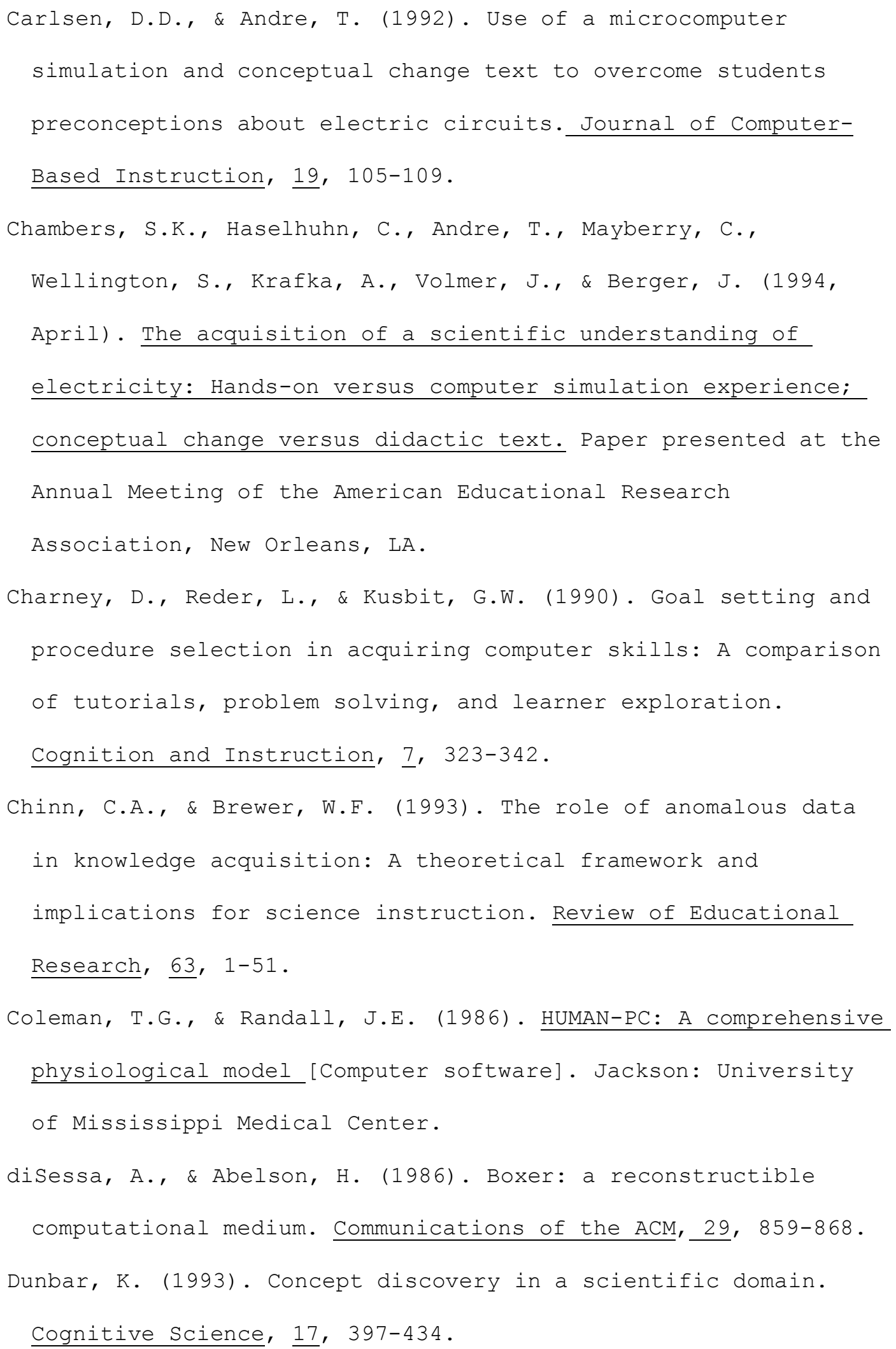


Scientific Discovery Learning with Computer Simulations

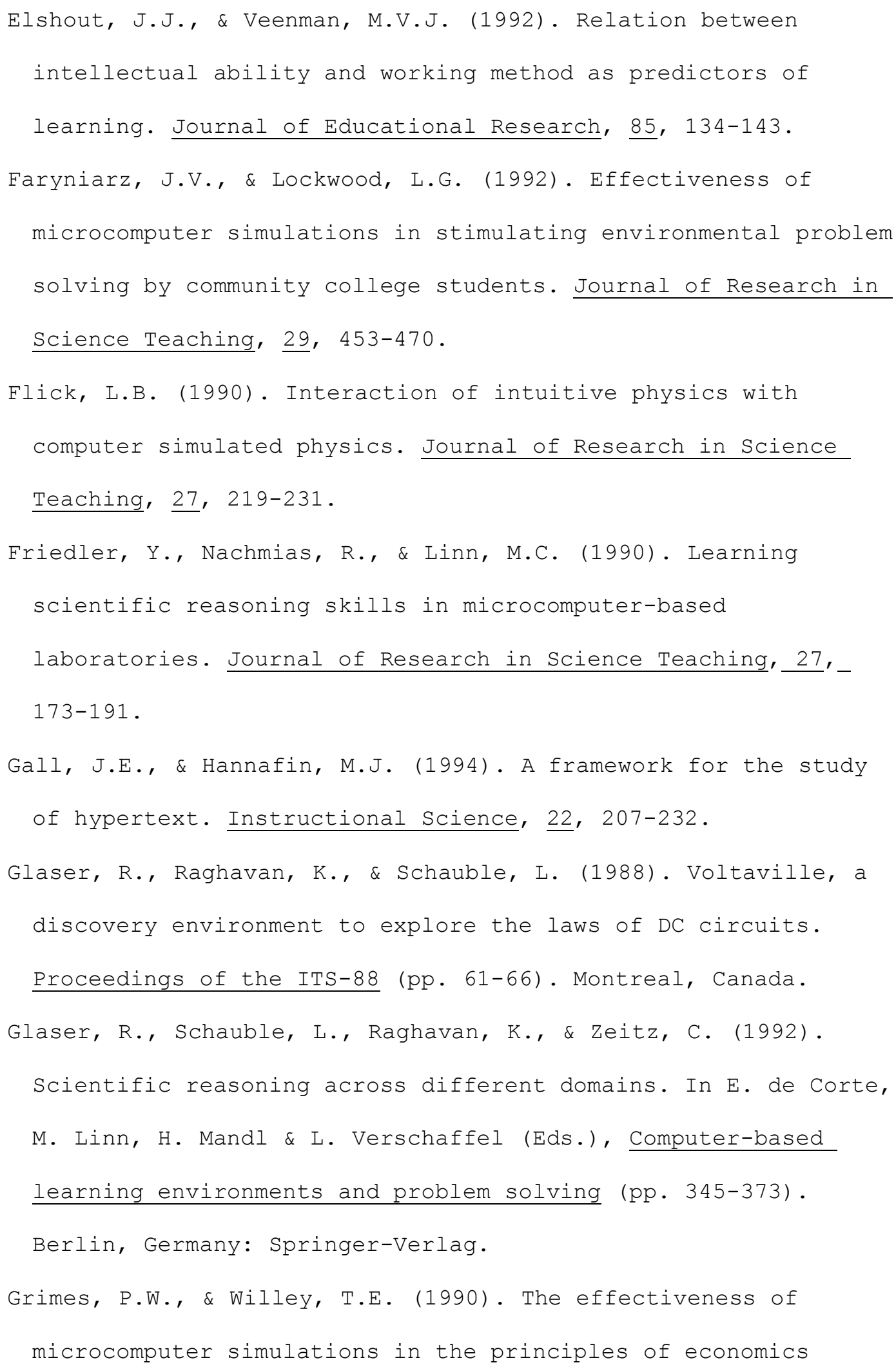


Scientific Discovery Learning with Computer Simulations

course. Computers \& Education, 14, 81-86.

Gruber, H., Graf, M., Mandl, H., Renkl, \& Stark, R. (1995,

August). Fostering applicable knowledge by multiple

perspectives and guided problem solving. Paper presented at

the conference of the European Association for Research on

Learning and Instruction, Nijmegen, The Netherlands.

Härtel, H. (1994). COLOS: Conceptual Learning of Science. In T.

de Jong \& L. Sarti (Eds.), Design and production of multimedia

and simulation based learning material (pp. 189-219).

Dordrecht, The Netherlands: Kluwer Academic Publishers.

de Jong, T. (1991). Learning and instruction with computer

simulations. Education \& Computing, 6, 217-229.

de Jong, T., Härtel, H., Swaak. J., \& van Joolingen, W. (1996).

Support for simulation-based learning; the effects of

assignments in learning about transmission lines. In A. Díaz

de Ilarazza Sánchez \& I. Fernández de Castro (Eds.), Computer

aided learning and instruction in science and engineering (pp.

9-27). Berlin, Germany: Springer-Verlag.

de Jong, T., van Joolingen, W., Scott, D., de Hoog, R. , Lapied,

L., Valent, R. (1994). SMISLE: System for Multimedia

Integrated Simulation Learning Environments. In T. de Jong \&

L. Sarti (Eds.), Design and production of multimedia and

simulation based learning material (pp. 133-167). Dordrecht,

The Netherlands: Kluwer Academic Publishers.

de Jong, T., Martin, E., Zamarro J-M., Esquembre, F., Swaak, J.,

\& van Joolingen, W.R. (1995, April). Support for simulation- 
Scientific Discovery Learning with Computer Simulations

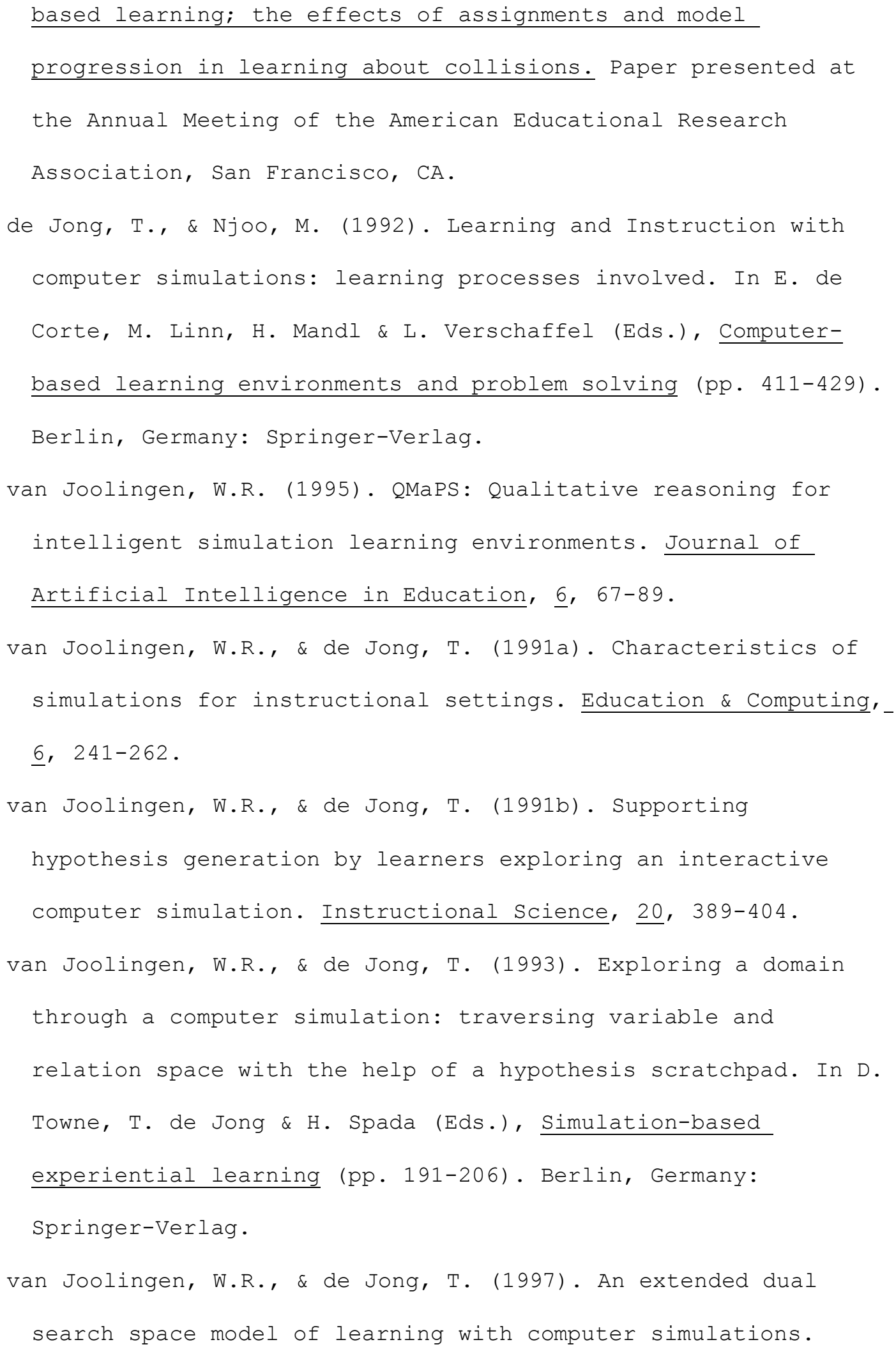


Scientific Discovery Learning with Computer Simulations

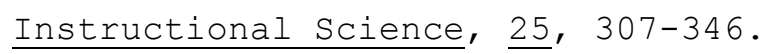

Kim, N., Evens, M., Michael, J.A., \& Rovick, A.A. (1989).

CIRCSIM-TUTOR: An intelligent tutoring system for circulatory

physiology. In H. Maurer (Ed.), Computer Assisted Learning.

Proceedings of the $2^{\text {nd }}$ International Conference ICCAL (pp. 254-

267). Berlin, Germany: Springer-Verlag.

Klahr, D., \& Dunbar, K. (1988). Dual space search during

scientific reasoning. Cognitive Science, 12, 1-48.

Klahr, D., Dunbar, K., \& Fay, A.L. (1991). Designing experiments

to test 'bad' hypotheses. In J. Shrager \& P. Langley (Eds.),

Computational models of discovery and theory formation (pp.

355-401). San Mateo, CA: Morgan-Kaufman

Klahr, D., Fay, A.L., \& Dunbar, K. (1993). Heuristics for

scientific experimentation: A developmental study Cognitive

Psychology, 25, 111-146.

Klayman, J., \& Ha, Y-W. (1987). Confirmation, disconfirmation,

and information in hypothesis testing. Psychological Review,

94, $211-228$.

Kozma, R.B., Russell, J., Jones, T., Marx, N., \& Davis, J.

(1996). The use of multiple, linked representations to

facilitate science understanding. In S. Vosniadou, E. De

Corte, R. Glaser \& H. Mandl (Eds.), International perspectives

on the design of technology supported learning environments

(pp. 41-61). Hillsdale, NJ: Erlbaum.

Kuhn, D., Schauble, L., \& Garcia-Mila, M. (1992). Cross-domain development of scientific reasoning. Cognition and 
Scientific Discovery Learning with Computer Simulations

Instruction, 9, 285-327.

Kulkarni, D., \& Simon, H. A. (1988). The processes of scientific discovery: The strategy of experimentation. Cognitive Science, $\underline{12}, 139-175$.

Lajoie, S.P. (1993). Cognitive tools for enhancing learning. In

S. P. Lajoie \& S.J. Derry (Eds.), Computers as cognitive tools (pp. 261-289). Hillsdale, NJ: Erlbaum.

Laurillard, D. (1992). Learning through collaborative computer simulations. British Journal of Educational Technology, 23, $164-171$

Lavoie, D.R., \& Good, R. (1988). The nature and use of predictions skills in a biological computer simulation. Journal of Research in Science Teaching, 25, 335-360. Lesgold, A., Lajoie, S., Bunzo, M., \& Eggan, G. (1992). SHERLOCK: A coached practice environment for an electronics troubleshooting job. In J.H. Larkin \& R.W. Chabay (Eds.), Computer-assisted instruction and intelligent tutoring systems: Shared goals and complementary approaches (pp. 201239). Hillsdale, NJ: Erlbaum.

Leutner, D. (1993). Guided discovery learning with computerbased simulation games: effects of adaptive and non-adaptive instructional support. Learning and Instruction, $\underline{3}$, 113-132. Lewis, E.L., Stern, J.L., \& Linn, M.C. (1993). The effect of computer simulations on introductory thermodynamics understanding. Educational Technology, $\underline{33}, 45-58$. Lindström, B., Marton, F., Ottosson, T., \& Laurillard, D. 
Scientific Discovery Learning with Computer Simulations

(1993). Computer simulations as a tool for developing

intuitive and conceptual understanding in mechanics. Computers in Human Behavior, 9, 263-281.

Linn, M.C., Layman, J., \& Nachmias, R. (1987). Cognitive consequences of microcomputer-based laboratories: Graphing skills development. Journal of Contemporary Educational $\underline{\text { Psychology }}, \underline{12}, 244-253$.

Linn, M.C., \& Songer, N.B. (1991). Teaching thermodynamics to middle school students: What are appropriate cognitive demands? Journal of Research in Science Teaching, 28, 885-918. Mandl, H., Gruber, H., \& Renkl, A. (1994). Problems of knowledge utilization in the development of expertise. In W.J. Nijhof \& J.N. Streumer (Eds.), Flexibility in training and vocational education (pp. 291-305). Utrecht, The Netherlands: Lemma BV Mayer, R.E. (1987). Educational psychology, a cognitive approach. Boston: Little, Brown and Company.

McDermott, L.C. (1990). Research and computer based instruction: Opportunity for interaction. American Journal of Physics, $\underline{58}$, $407-415$

Michael, J.A., Haque, M.M., Rovick, A.A., \& Evens, M. (1989). The pathophysiology tutor: a first step towards a smart tutor. In H. Maurer (Ed.), Computer Assisted Learning. Proceedings of the $2^{\text {nd }}$ International Conference ICCAL (pp. 390-400). Berlin, Germany: Springer-Verlag .

Mokros, J.R., \& Tinker, R.F. (1987). The impact of microcomputer based labs on children's ability to interpret graphs. Journal 
Scientific Discovery Learning with Computer Simulations

of Research in Science Teaching, 24, 369-383.

Munro, A., Fehling, M.R., \& Towne, D.M. (1985). Instruction

intrusiveness in dynamic simulation training. Journal of

Computer-Based Instruction, $\underline{2}$, 50-53.

Njoo, M., \& de Jong, T. (1993a). Exploratory learning with a

computer simulation for control theory: Learning processes and

instructional support. Journal of Research in Science

Teaching, $30,821-844$.

Njoo, M., \& de Jong, T. (1993b). Supporting exploratory learning

by offering structured overviews of hypotheses. In D. Towne,

T. de Jong \& H. Spada (Eds.), Simulation-based experiential

learning (pp. 207-225). Berlin, Germany: Springer-Verlag.

Novak, J.D., \& Wandersee, J.H. (1990). Perspectives on concept

mapping (special issue). Journal of Research in Science

Teaching, 27, 921-1079.

Qin, Y., \& Simon, H.A. (1990). Laboratory replication of

scientific discovery processes. Cognitive Science, 14, $281-$

312 .

Quinn, J., \& Alessi, S. (1994). The effects of simulation

complexity and hypothesis generation strategy on learning.

Journal of Research on Computing in Education, 27, 75-91.

Reigeluth, C.M., \& Schwartz, E. (1989). An instructional theory

for the design of computer-based simulations. Journal of

Computer-Based Instruction, 16, 1-10.

Reimann, P. (1991). Detecting functional relations in a

computerized discovery environment. Learning and Instruction, 
Scientific Discovery Learning with Computer Simulations

1, 45-65.

Reimann, P., \& Beller, S. (1993). Computer-based support for analogical problem solving and learning. In D.M. Towne, T. de Jong \& H. Spada (Eds.), Simulation-based experiential learning (pp. 91-105). Berlin, Germany: Springer-Verlag.

Rieber, L.P. (1990). Using computer animated graphics in science instruction with children. Journal of Educational Psychology, $\underline{82}, 135-140$

Rieber, L.P. (1996). Animation as feedback in a computer-based simulation: representations matter. Educational Technology

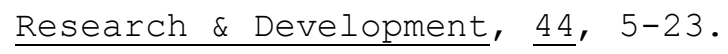

Rieber, L.P., Boyce, M., \& Assad, C. (1990). The effects of computer animation on adult learning and retrieval tasks. Journal of Computer-Based Instruction, 17, 46-52.

Rieber, L.P., \& Parmley, M.W. (1995). To teach or not to teach? Comparing the use of computer-based simulations in deductive versus inductive approaches to learning with adults in science. Journal of Educational Computing Research, 14, 359374

Rieber, L.P., Smith, M., Al-Ghafry, S., Strickland, B., Chu, G., \& Spahi, F. (1996). The role of meaning in interpreting graphical and textual feedback during a computer-based simulation. Computers \& Education, 27, 45-58.

Riley, D. (1990). Learning about systems by making models. Computers \& Education, 15, 255-263. Rivers, R.H., \& Vockell, E. (1987). Computer simulations to 
Scientific Discovery Learning with Computer Simulations

stimulate scientific problem solving. Journal of Research in Science Teaching, 24, 403-415.

Schauble, L., Glaser, R., Duschl, R.A., Schulze, S., \& John, J. (1995). Students' understanding of the objectives and procedures of experimentation in the science classroom. The Journal of the Learning Sciences, 노 131-166.

Schauble, L., Glaser, R., Raghavan, K., \& Reiner, M. (1991). Causal models and experimentation strategies in scientific reasoning. The Journal of the Learning Sciences, 1 , 201-239. Schauble, L., Klopfer, L., \& Raghavan, K. (1991). Students' transitions from an engineering to a science model of experimentation. Journal of Research in Science Teaching, 28, $859-882$

Schauble, L., Raghavan, K., \& Glaser, R. (1993). The discovery and reflection notation: A graphical trace for supporting self regulation in computer-based laboratories. In S. P. Lajoie \& S.J. Derry (Eds.), Computers as cognitive tools (pp. 319-341). Hillsdale, NJ: Erlbaum.

Showalter, V.M. (1970). Conducting science investigations using computer simulated experiments. The Science Teacher, 37, 4650 .

Shute, V.J. (1993). A comparison of learning environments: All that glitters... In S.P. Lajoie \& S.J. Derry (Eds.), Computers as cognitive tools (pp. 47-75). Hillsdale, NJ: Erlbaum.

Shute, V.J., \& Glaser, R. (1990). A large-scale evaluation of an intelligent discovery world: Smithtown. Interactive Learning 
Scientific Discovery Learning with Computer Simulations

Environments, $1,51-77$.

Simmons, P.E., \& Lunetta, V.N. (1993). Problem-solving behaviors during a genetics computer simulation: beyond the

expert/novice dichotomy. Journal of Research in Science

$\underline{\text { Teaching }}, \underline{30}, 153-173$.

Simon, H.A., \& Lea, G. (1974). Problem solving and rule

induction: a unified view. In L.W. Gregg (Ed.), Knowledge and

cognition (pp. 105-128). Hillsdale, NJ: Erlbaum.

Smith, R.B. (1986). The Alternate Reality Kit: An animated

environment for creating interactive simulations. Proceedings

of IEEE Computer Society Workshop on Visual Programming (pp.

99-106). Dallas, TX.

Suthers, D., Weiner, A., Connelly, J., \& Paolucci, M. (1995).

Belvedere: Engaging students in critical discussion of science

and public policy issues. In J. Greer (Ed.), Proceedings of

the AI-Ed 95, the 7th World Conference on Artificial

Intelligence in Education (pp. 266-273). Charlottesville, VA:

AACE .

Swaak, J., \& de Jong, T. de (1996). Measuring intuitive

knowledge in science: the what-if test. Studies in Educational

Evaluation, 22, 341-362.

Swaak, J., van Joolingen, W.R., \& de Jong, T. (1996). Support

for simulation based learning; The effects of model

progression and assignments on learning about oscillatory

motion. Enschede, The Netherlands: University of Twente,

Centre for Applied Research on Education. 
Tabak, I., Smith, B.K., Sandoval, W.A., \& Reiser, B.J. (1996). Combining general and domain-specific strategic support for biological inquiry. In C. Frasson, G. Gauthier \& A. Lesgold (Eds.), Intelligent Tutoring Systems (pp. 288-297). Berlin, Germany: Springer-Verlag .

Tait, K. (1994). DISCOURSE: The design and production of simulation-based learning environments. In T. de Jong \& L. Sarti (Eds.), Design and production of multimedia and simulation-based learning material (pp. 111-133). Dordrecht, The Netherlands: Kluwer Academic Publishers. Teodoro, V. D. (1992). Direct manipulation of physical concepts in a computerized exploratory laboratory. In E. de Corte, M. Linn, H. Mandl \& L. Verschaffel (Eds.), Computer-based learning environments and problem solving (NATO ASI series F: Computer and Systems Series) (pp. 445-465). Berlin, Germany: Springer-Verlag.

Thomas, R., \& Hooper, E. (1991). Simulations: an opportunity we are missing. Journal of Research on Computing in Education, 23, $497-513$.

Thomas, R., \& Neilson, I. (1995). Harnessing simulations in the service of education: the Interact simulation environment. Computers \& Education, 25, 21-29.

Thurman, R.A. (1993). Instructional simulation from a cognitive psychology viewpoint. Educational Technology Research \& Development, $\underline{41}, 75-89$. Thurman, R.A., \& Mattoon, J.S. (1994). Virtual reality: Towards 
Scientific Discovery Learning with Computer Simulations

fundamental improvements in simulation-based training.

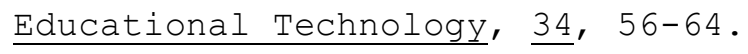

Towne, D.M. (1995). Learning and instruction in simulation

environments. Englewood Cliffs, NJ: Educational Technology

Publications.

Veenman, M.V.J., \& Elshout, J.J. (1995). Differential effects of instructional support on learning in simulation environments. Instructional Science, 22, 363-383.

Veenman, M.V.J., Elshout, J.J., \& Busato, V.V. (1994).

Metacognitive mediation in learning with computer-based

simulations. Computers in Human Behavior, 10, 93-106.

Wason, P.C. (1960). On the failure to eliminate hypotheses in a conceptual task. Quarterly Journal of Experimental Psychology, $\underline{12}, 129-140$.

Wason, P.C. (1966). Reasoning. In B.M. Foss (Ed.), New horizons in Psychology (pp. 135-151). Harmondsworth, United Kingdom: Penguin.

White, B.Y. (1984). Designing computer games to help physics students understand Newton's laws of motion. Cognition and Instruction, 1 , 69-108.

White, B.Y. (1993). ThinkerTools: causal models, conceptual change, and science education. Cognition and Instruction, $\underline{10}$, $1-100$

White, B.Y., \& Frederiksen, J.R. (1989). Causal models as intelligent learning environments for science and engineering education. Applied Artificial Intelligence, 3(2-3), 83-106. 
Scientific Discovery Learning with Computer Simulations

White, B.Y., \& Frederiksen, J.R. (1990). Causal model

progressions as a foundation for intelligent learning

environments. Artificial Intelligence, 42, 99-157.

Whitelock, D., Taylor, J., O'Shea, T., Scanlon, E., Sellman, R., Clark, P., \& O'Malley, C. (1993). Challenging models of elastic collisions with a computer simulation. Computers \& $\underline{\text { Education, }}$ 20, $1-9$.

Woodward, J., Carnine, D., \& Gersten, R. (1988). Teaching problem solving through computer simulations. American $\underline{\text { Educational Research Journal, }} \underline{25}, 72-86$.

Zietsman, A.I., \& Hewson, P.W. (1986). Effect of instruction using microcomputers simulations and conceptual change strategies on science learning. Journal of Research in Science Teaching, 23, 27-39. 
Scientific Discovery Learning with Computer Simulations

Author Notes

Address correspondence to: Ton de Jong, Faculty of Educational Science and Technology, University of Twente, Po Box 217, 7500 AE Enschede, The Netherlands. Email: jongeedte.utwente.nl. Part of the work presented was carried out within the SAFE/SIMULATE, the SMISLE, and the SERVIVE projects. These projects were partially sponsored by the European Commission in its Telematics programmes. We appreciate the contribution of our colleagues from these projects to the work presented here, especially Jules Pieters and Janine Swaak (University of Twente), Melanie Njoo (now at Origin/Instruction Technology), Anja van der Hulst (now at TNO Physics and Electronics Laboratory) and Robert de Hoog (University of Amsterdam). Jules Pieters, Jeroen van Merriënboer (University of Twente), Patricia Alexander (University of Maryland), and Simon King (EDS-Ingévision) provided us with helpful comments on a draft version of this article. 